\title{
Directness vs. Indirectness: A Study of the Linguistic Choices of Persian Speakers When Giving Advice
}

\author{
Mohammad Aliakbari ${ }^{1}$, Raziyeh Aghaee $^{1}$ \& Fatemeh AzimiAmoli $^{1}$ \\ ${ }^{1}$ Department of English, Ilam University, Ilam, Iran \\ Correspondence: Mohammad Aliakbari, Faculty of Literature, Ilam University, Ilam, Iran. E-mail: \\ maliakbari@hotmail.com \\ Received: May 30, 2015 \\ Accepted: June 15, 2015 \\ Online Published: June 16, 2015 \\ doi:10.5430/elr.v4n2p55 \\ URL: http://dx.doi.org/10.5430/elr.v4n2p55
}

\begin{abstract}
Considering lack of research in communication style in Persian and drawing upon Tannen's conversational style theory (1984), this study aimed at investigating the degree of indirectness in Persian by focusing on the giving-advice speech act. To this end, the data were collected through a multiple choice Discourse Completion Test (DCT), developed and designed by the researchers. The results indicated that, except for gender, other variables such as age, status, and social distance of the interlocutors had a significant effect on the linguistic choices of the participants and on their directness score. The findings, thus confirmed the efficacy of Tannen's conversational style theory in justifying the functions of indirectness in Persian.
\end{abstract}

Keywords: Directness, Indirectness, Advice giving, Linguistic choices

\section{Introduction}

The rules of pragmatics determine the choice of the accepted language forms that fit various contexts. Such rules or norms of language usage are not usually taught as a component of language to enable language learners to communicate more efficiently with the speakers of the target language. Therefore, ignorance of these rules often impedes successful communication or causes communication breakdown (Wilson, 1987a) or pragmatic failure (Thomas, 1983; Martinez-Flor, 2005; Decapua \& Dunham, 2007; Pishghadam \& Sharafadini, 2011). Learners may resort to their native cultural norms to determine their choice of the target language forms. They often use 'negotiating strategies' (Long, 1983) in speaking to the native speakers. If the choice deviates from the norm of the target language, learners may be misunderstood and embarrassed (Thomas, 1983). To put it in Borger and Seaborne (1967, p.156) words, "Confusion is greatest when on separate occasions people are called upon to behave different ways under similar circumstances."

Aufa (2013) conducted a study to investigate the effectiveness of discourse completion test as explicit pragmatic instruction to facilitate second language learners in developing their pragmatic competence. The findings indicated instruction of forms can aid to the development of learners' pragmatic competence. In the same vein, Chen (2009) pointed out learners with explicit instruction carry out better than those who get implicit instruction.

As strangers to the target language culture and having 'communicative anxiety' (Littlewood, 1983), learners usually strive to show politeness in order to get attention and cooperation from the native speakers of a second language (L2) to achieve successful communication with them. However, learners may need to use that area of communicative competence where culturally based norms often come into conflict in the expression of politeness in the target language. In her review of current research on linguistic politeness, Kasper (1990) confirms the idea that non-native speakers may not have politeness where it is expected, and may use it where it is not expected, because of being less competent and consequently vulnerable to the risk of inadvertently violating politeness norms, and thereby forfeiting their claim to being treated as social equals.

A wide range of communication aspects have been the focus of intracultural and cross-cultural studies. Among these aspects, communication styles, also referred to as linguistic strategies, including indirectness, silence vs. volubility, topic raising, interruption, and adversativeness or verbal conflict, have drawn the attention of several researchers (Zimmerman \&West, 1975; Esposito, 1979; Spender, 1980; Shuy, 1982; Sattel, 1983; James \& Clarke, 1993; Tannen, 1994; Jaworski, 1998; Li, 2001; Li et al., 2005; Arcidiacono \&Pontecorvo, 2009). Using communication styles in any form and with any function in language provides information about that language and the people who are using it 
consciously or unconsciously to communicate. These unspeakable messages, as Tannen (1990) called metamessages, reveal some facts about the difference between speakers' linguistic choices in different institutions or with different interlocutors. Relevant to the area of the current study, the aspect of indirectness as a communication style is of paramount importance as a metamessage in uncovering hidden aspects of communication. For example, several studies have claimed that the feminine speaker style is more indirect than that of men (Lakoff, 1975; Goodwin, 1980; Tannen, 1990, 1994; Holmes, 2001) and De Francisco and Palczewski (2007) claimed that people with lower social status are more probable to use indirectness (p.70). Yet, Tannen (1994) argued that indirectness is not a sign of powerlessness, and that it can be seen as a sign of power instead.

Considering the fact that indirectness is frequently used in different forms, with different functions in Persian, uncovering its hidden aspects of communication by focusing on indirect conversation can be helpful in understanding Iranian people and their native language. It may also generally contribute to evaluate the overall theories on direct and indirect speech acts. To this end, the present study investigated the degree of indirectness in giving advice as a kind of speech act in Persian language, by considering the role of gender, age, social distance, and status of the interlocutors.

\subsection{Functions of indirectness in interactions}

Zhang and You (2009) considered indirectness as "the means in which one's meaning is conveyed indirectly through utterances or non-verbal behaviors in order to achieve certain goal, or the means in which one's intent is revealed in a roundabout way" (p. 99). Many scholars have tried to explain directness/indirectness phenomenon through context model, conversational style theory, and politeness theory. The following sections provide a brief introduction to each model, respectively. Further, to account for the role of indirectness in each model, the studies which adopted these models in examining directness/indirectness have also been pointed out.

\subsection{Politeness Theory}

The politeness theory first proposed by Brown and Levinson (1987) and put emphasis on the close relationship of indirectness and politeness. The notion of face, which is a basic concept in this theory, is defined by Renkema (2004) as "the image that a person projects in his social contacts with others". When we are involved in a conversation, it is necessary to keep one's own face or to avoid threatening another's face. Some speech acts such as requesting, apologizing, reprimanding, refusing, and giving advice are intrinsically face-threatening acts (FTA's). Interlocutors often try to employ some politeness strategies in their interactions in order to keep their face and to avoid damaging the hearer's face. Indirectness can be regarded as one of these politeness strategies, mitigating the severity of the probable damage to the interlocutors' face. Therefore, it is clear that politeness necessarily calls for indirectness.

Many authors studied the notion of indirectness as a politeness strategy from the perspective of politeness theory (Sifiano, 1992; Ružicková, 1998; Márquez-Réiter, 2000; Wierbzicka, 2003; Félix-Brasdefer, 2005; Cheng, 2009 Mwinyelle, 2005 \&Borderia- Garcia, 2006).

In Iran, Eslami-Rasekh (1993), Salmani-Nodoushan (2008), and Eslami-Rasekh et al (2010) have studied indirectness in the speech act of requests. Salmani-Nodoushan (2008) adopted politeness theory and the notion of face to investigate the notion of indirectness in the speech act of requests among native speakers of Persian across different levels of perceived situational seriousness. Adapting the same theory, Eslami-Rasekh et al. (2010) focused on the similarities and differences between Americans and Iranians with regard to the speaker's assumed expectations of compliance in selecting among the conventionally indirect spectrum. They concluded that, in comparable situations, the Americans were generally more certain that the addressee would comply with the request than Iranians. They, therefore, argued that conventional indirectness appears to reflect different social meanings in English and Persian and those differences should be taken into account in EFL instruction and in cross-cultural studies.

\subsection{Indirectness in Speech Acts}

Searle (1975) introduced the notion of 'indirect speech acts'. This notion is applied to speech acts in which the speaker communicates to the hearer more than transferring his own message by means of relying on their common cultural background information such as requesting, refusing, apologizing, etc. The rational for choosing the speech act of giving advice was that in Persian, advice giving, which is mostly a benevolent reaction to the others' true or probable mistakes, often calls for indirection. This reaction, depending on certain factors, is often reflected in four linguistic choices of silence, direct advice, indirect advice, and very indirect act.

Furthermore, although many researchers have shown interest in the study of speech acts in Persian to find out the participants' behavior in performing speech acts (e. g., Eslami-Rasekh, 1993; Salmani-Nodoushan, 2008; Salmani- 
Nodoushan\&Allami, 2011 (requesting); Allami, 2006 (griping); Salmani-Nodoushan; 2006 (inviting); Afghari, 2007; Shariati \&Chamani, 2009 (apologizing); Eslami-Rasekh, 2004; Salmani-Nodoushan, 2008 (complaining); Allami, 2010; Aliakbari\&Changizy, 2011 (refusal); Aliakbari, Heidarizad \&Mahjub, 2011 (Swearing); Hassani, et al. 2011 (refusing); Eslami-Rasekh \&Ahmadian, 2011 (reprimanding)), it has been a neglected area in Persian. Thus, giving advice was selected as a speech act which mirrors the Iranians' behavior when selecting a direct or indirect style.

By considering the afore-mentioned issues, this phenomenon has been studied from different perspectives. Sociolinguists focused on the study of indirectness mainly from the perspective of politeness. Yet, when individuals from different cultures practice politeness in conversations, they are often influenced by their own specific culture. As a result, leaving the study of indirectness to politeness- oriented research is not recommended. Also, as some researchers (e.g., Gudykunst; 1983; Gudykunst\& Nishida, 1986; Cardon, 2008) argued, Hall's model simplifies the interpretation of directness/indirectness by dividing the cultures into $\mathrm{HC}$ and $\mathrm{LC}$ cultures and ignoring the effect of situation and context. Accordingly, in attempt to investigate the issue from a different perspective, the present study adopted Tannen's conversational style theory to examine the Iranian's hidden aspects of communication or nonverbal messages in performing advice giving speech act.

\subsubsection{Giving Advice in Speech Acts}

Locher (2006) created a wide study of advice-giving in an internet advice base that was part of the health program. Advice-seekers could send questions about most any health-related matter and receive a response written by a group of health educator. Locher's (2006) book, Advice Online, debates the content structure of advice letters, aspects of relational, the personal and public dimension of advice-giving in the letters, and the problem letters by the advice-seekers. In the sections on content structure, Locher (2006: 76) stated some findings that can be contrasted to the results of the present study. She discovered that advice were the most frequent type of discursive move, and remarked that there was a typical pattern in this evaluation (Locher, 2006: 85).

According to Brown and Levinson's (1987), the discourse strategies related to advice-giving in English have usually been to relieve the face threatening act of giving advice. However, Haugh $(2004,2006$, and 2007) indicate there have been some questions about the appropriateness of applying Brown and Levinson's politeness theory to Japanese because advice-giving may be seen as a positive expression of concern in Asian culture. It seems presumably that advice-giving is depends on contextual situations in both English and Japanese. What is obvious is that Japanese advice-givers utilize the same strategies as those used for advice-giving in English in the same context. Because some of them are utilized frequently, they may be taken into account specified properties of advice-giving in the Rikon discussion.

Spencer-Oatey (2005) illustrates that few studies have been carried out how a specific speech act (advice in this case) is used in a larger context and seek to describe sociolinguistic and pragmalinguistic strategies Spanish L2 learners' use in an advice-giving situation with a native speaker. The findings displayed the impact of a semester abroad on L2 interlanguage development and provided information to determine where pedagogy could play a role in guiding learners to understand pragmatic awareness in an advice situation.

According to Watts (2003) and Bordería-García (2006), many studies have displayed that non-native speakers' attitudes toward speech act differed from various studies on () giving advice (; Chun, 2009). According to Al-Shboul and Zarei (2013), the perception in giving advice with the influence of gender among Iranian learner represented they were different in terms of the types of advice they showed as the appropriate choice.

\subsection{Rational For the Study}

Many researchers have supported the idea that context contributes to meaning (e. g., Lakoff, 1977; Leech, 1983; Kasper, 1996; Charlebois, 2004). Tannen (1984) believes that communication in any culture is a matter of directness which means that the way people interpret indirect and direct conversation and their motives for an indirect or direct statement is cross-culturally different. Therefore, indirectness can cause confusion when the interlocutors are using different styles. Considering these conditions, it seems that the study of indirectness in any language is necessary for preventing miscommunication in international communications.

In addition, communication styles, in general, and indirectness, in particular, have been neglected in Persian. Therefore, the present research aims at examining the forms and degree of indirectness as one aspect of Persian communication style in the speech act of advice giving.

Based on the above objectives, the following research questions were raised:

(1) How are Persian speakers' directness/ indirectness linguistic choices distributed across different situations? 
(2) According to the perceptions of the respondents, do such factors as age, status, and social distance of interlocutors significantly influence speakers' degree of directness/indirectness in giving advice?

(3) Is there any significant difference between males and females in using directness strategy?

\section{Method}

\subsection{Participants}

In order to collect data, convenience sampling method was used. Participants included 240 adults from Bandar Imam, Iran, (140 males and 100 females), ranging from 18 to 58 years old (mean age: 39 for males and 32 for females). All participants were native Persian speakers. The selected samples were different in terms of education (ranging from under diploma to a postgraduate degree) and occupation (including university students, drivers, officers, accountants, salespersons, teachers, and attorneys).

\subsection{Instruments}

As the situations described in other DCTs, for example, the one developed by Hinkel (1997), seems not to be applicable for Iranian context, a new version of DCT was designed by the researchers in order to evaluate indirectness in giving advice speech act. The adopted DCT included 13 situations demanding reaction to a wrong act (giving advice). Among them, two situations was related to giving advice to an interlocutor of equal statues, three to an intimate interlocutor, three to an interlocutor older than the respondents, two to an interlocutor younger than respondents, and finally three situations to a higher statues interlocutor. Further, as the researchers believed that the nature of some situations such as high status necessitated the allocation of more items than the other situations in order to be certain about the consistency of responses across these situations, a different number of items were selected for each situation. In the present study, to increase the validity of the questionnaire, Multiple Choice (MC) options were taken from pilot DCT, and the MC instrument was constructed according to real and observed situations in which the speech act of giving advice was performed in Persian. In other words, production responses served as the basis for MC design and development. Finally, regarding the reliability of the questionnaire, the result of data analysis during the pilot testing indicated that the instrument is reliable $(\alpha=.82)$.

\subsection{Procedure}

First, in order to make sure that the respondents are not negatively affected as a result of participating in this research, they were assured of the confidentiality of the collected data.

To answer the first research question, the frequency of each option for all five categories including higher status, equal status, intimate, older, and younger interlocutors were calculated and presented by percentage to see in which situations they preferred to be silent, advice directly, advice indirectly, and act very indirectly. Chi- square test was used to see whether there is any significant difference among the categories or not. Regarding the second research question, the scoring method designed by Nelson et al. (2002) was implemented to answer the question. For example, if a respondent reacted to a wrong act by a direct advice giving, 1 was given while 0 was given for other cases. Total directness score for each respondent was calculated by summing the assigned directness score for each situation. For example, total scores within high-status situation were calculated with a maximum of 3 (i.e., all of the three advice giving situations for higher status included a direct linguistic choice) and a minimum of 0 (i.e., none of the advice giving situations for high status included a direct linguistic choice). The same procedure was used to calculate directness score within each age situation and in social distance (intimate interlocutor). In general, each subject had five directness scores including higher status situations, equal status, intimate interlocutor, older interlocutor, and younger interlocutor. Then, directness score mean in each situation was calculated. Finally, in order to see whether there is any significant difference among directness score means in the described situations, these five groups of scores were compared through analysis of variances (ANOVA). Also, in order to study the directness among male and female participants, the mean of both groups were compared using independent sample t-test.

\section{Results}

Data were analyzed to find answers for the research questions. In so doing, the relevant tests and statistical procedures were run. In order to find the answer for the first research question, the frequency of different options chosen by the participants in all five categories of situations was counted and presented in Table 1. As it is evident in Table1, the distribution of four linguistic choices across the situations of the instrument is different. 
Table 1. The Distribution of Four Linguistic Choices in Each Situation of the Instrument

\begin{tabular}{|c|c|c|c|c|c|c|c|c|c|c|}
\hline & Ling & listic cho & ices & & & & & & & \\
\hline \multirow{2}{*}{ Situation } & \multicolumn{2}{|c|}{ Silence } & \multicolumn{2}{|c|}{ Advice D } & \multicolumn{2}{|c|}{ Advice I } & \multicolumn{2}{|c|}{ Act very I } & \multicolumn{2}{|l|}{ Total } \\
\hline & $f$ & $\%$ & $f$ & $\%$ & $f$ & $\%$ & $f$ & $\%$ & $f$ & $\%$ \\
\hline Giving advice to an ESI & 10 & $2.1 \%$ & 280 & $58.3 \%$ & 130 & $27.8 \%$ & 60 & $12.5 \%$ & 480 & 100 \\
\hline Giving advice to an HSI & 138 & $19.2 \%$ & 54 & $7.5 \%$ & 286 & $39.7 \%$ & 242 & $33.6 \%$ & 720 & 100 \\
\hline Giving advice to an II & 16 & $2.2 \%$ & 348 & $48.3 \%$ & 164 & $22.7 \%$ & 192 & $26.7 \%$ & 720 & 100 \\
\hline Giving advice to an OI & 58 & $8.5 \%$ & 182 & $25.3 \%$ & 214 & $29.2 \%$ & 266 & $36.9 \%$ & 720 & 100 \\
\hline Giving advice to a YI & 2 & $0.4 \%$ & 358 & $74.6 \%$ & 76 & $15.9 \%$ & 44 & $9.2 \%$ & 480 & 100 \\
\hline Total & 224 & $7.2 \%$ & 1222 & $39.2 \%$ & 870 & $27.9 \%$ & 804 & $25.8 \%$ & 3120 & 100 \\
\hline
\end{tabular}

Note. Bolds present the highest percentage of linguistic choices in each situation. $\mathrm{f}=$ frequency; $\mathrm{a} \%=$ percentage; ESI= equal status interlocutor; $\mathrm{HSI}=$ higher status interlocutor; $\mathrm{II}=$ intimate interlocutor; $\mathrm{OI}=$ older interlocutor; $\mathrm{YI}=$ younger interlocutor; $\mathrm{D}=$ directly; $\mathrm{I}=$ indirectly.

To determine the level of significance, 5 chi- square tests compatible to five situations described in the questionnaire were run. The results are summarized in Table 2. According to Table2, the variant distribution of linguistic choices across all the five situations of the instrument is statistically significant $(D F=3, p=.00)$.

Table 2. The Results of Chi-Square Tests for Evaluating the Significance of Variant Frequencies of Linguistic Choices across the Situations

\begin{tabular}{llll}
\hline Situations & $\chi^{2}$ & $d f$ & $p$ \\
\hline Giving advice to an interlocutor of Equal status & 345.000 & 3 & $.00^{*}$ \\
Giving advice to an Interlocutor of Higher status & 181.778 & 3 & $.00^{*}$ \\
Giving advice to an Intimate interlocutor & 308.444 & 3 & $.00^{*}$ \\
Giving advice to an Older interlocutor & 130.222 & 3 & $.00^{*}$ \\
Giving advice to a Younger interlocutor & 652.333 & 3 & $.00^{*}$ \\
\hline
\end{tabular}

\section{$* p<.05$}

In order to examine the respondents' directness scores across situations, five directness score means compatible with five situations of the instrument were calculated. Table 3 represents the results. As Table 3 shows, when interlocutor is in a higher status, participants' directness score had the smallest mean (0.23) and when interlocutor is a younger person, they had the greatest mean (1.54). The mean results can be sorted in this way: (higher status $<$ older $<$ equal status $<$ intimate $<$ younger).

Regarding the second research question, to see whether the observed difference in the directness mean scores is statistically significant or not, the five groups of scores were compared by ANOVA test. The results showed that there is a significant difference between different groups' mean $(D F=4, p=.00)$. In conclusion, , status, social distance, and age of the interlocutors which are regarded as the variant factors of five situations described in the DCT had significant effect on the indirectness degrees of Persian speakers when giving advice. 
Table 3. Calculated Means for the Five Groups of Directness Scores

\begin{tabular}{|c|c|c|c|c|c|c|c|c|c|}
\hline \multirow[b]{2}{*}{ Situation } & \multicolumn{3}{|c|}{ Directness score } & \multicolumn{3}{|l|}{$\mathrm{N}$} & \multicolumn{3}{|c|}{ Mean } \\
\hline & $\mathrm{m}$ & $\mathrm{F}$ & $\mathrm{T}$ & $\mathrm{m}$ & $\mathrm{F}$ & $\mathrm{t}$ & $\mathrm{m}$ & $\mathrm{f}$ & $\mathrm{t}$ \\
\hline high-status interlocutor & 34 & 22 & 56 & 140 & 100 & 240 & 0.24 & 0.22 & 0.23 \\
\hline equal status interlocutor & 168 & 106 & 274 & 140 & 100 & 240 & 1.2 & 1.06 & 1.14 \\
\hline intimate interlocutor & 180 & 164 & 344 & 140 & 100 & 240 & 1.28 & 1.64 & 1.43 \\
\hline Older interlocutor & 108 & 66 & 174 & 140 & 100 & 240 & 0.77 & 0.66 & 0.72 \\
\hline younger interlocutor & 220 & 150 & 370 & 140 & 100 & 240 & 1.57 & 1.5 & 1.54 \\
\hline Total & 708 & 506 & 1214 & 140 & 100 & 240 & 5.05 & 5.06 & 5.05 \\
\hline
\end{tabular}

Note. $\mathrm{f}=$ female; $\mathrm{m}=$ male; $\mathrm{t}=$ total; and $\mathrm{N}=$ the number of scores.

Finally, to answer the third research question, the total directness score means of males and females as well as their directness score means in all the separately scored situations were compared using t-tests. The results of the t- tests are summarized in Table 4. The results revealed no significant effects of gender on total directness score when males and females were compared. However, testing their directness scores across situations did uncover significant effect of gender in intimate situation $(D F=238, p=.007)$. As the calculated means for the intimate situation shows, female participants are more direct than males (1.64>1.28).

Table 4. T-Test Results for Comparing Males' and Females' Directness Score Means

\begin{tabular}{|c|c|c|c|c|c|}
\hline \multirow[b]{2}{*}{ Situations } & \multicolumn{2}{|c|}{ Mean } & \multirow[t]{2}{*}{$\mathrm{t}$} & \multirow[t]{2}{*}{$D f$} & \multirow[t]{2}{*}{$p$} \\
\hline & $\mathrm{F}$ & & & & \\
\hline High status & 0.22 & 0.24 & 0.41 & 238 & 0.67 \\
\hline Equal status & 1.06 & 1.2 & 1.68 & 238 & 0.09 \\
\hline Intimate & 1.64 & 1.28 & 2.72 & 238 & $0.007 *$ \\
\hline Older & 0.66 & 0.77 & 1.22 & 238 & 0.22 \\
\hline Younger & 1.5 & 1.57 & 0.90 & 238 & 0.36 \\
\hline Total & 5.06 & 5.05 & 0.01 & 238 & 0.99 \\
\hline
\end{tabular}

Note. $\mathrm{f}=$ female; $\mathrm{m}=$ male.

$*_{p}<.05$

\section{Discussion}

As the results indicated, the frequency of linguistic choices was different among the participants. Approximately $93 \%$ of respondents directly or indirectly showed reaction to the others' true or probable mistakes and only about $7 \%$ of them preferred to be silent. This observation (i.e. high frequency of reaction to a wrong act vs. low frequency of silence) may be attributed to the Iranian's collectivistic and Islamic values according which people concerns each other's fortune and destiny. In addition to the difference between the total frequencies of linguistic choices in respondents' answers, the frequencies of these linguistic forms were also different across situations of the instrument. As evident from Table1, the most discrepancy is observable in selecting the linguistic choice of "to be silent". More than 60 per cent of selecting being silent occurred in higher status situation. This fact shows that although the collectivistic values are dominant in Iranian society, in high status, situation the Iranians preferred to close the eyes to them. The results also revealed that the lowest degree of directness occurred in the situation of giving advice to a higher status interlocutor. Therefore, Persian speakers are often indirect and/or silent in this situation. However when the interlocutor was of equal status respondents demonstrated more degree of directness than the situation in which interlocutors were not of the same status. Through the literature, the issue of relationship between the degree of 
indirectness and the status of interlocutors has not lead to a consensus. The findings of the present study are consistent with the results of other researchers (e.g., Katriel, 1986) who noted that with increase the status of interlocutors, the degree of indirectness increases as well. Also, according to the results of mean comparison tests, when the interlocutor was older than the respondents, the directness score mean for this situation was less than half of directness score mean of younger interlocutor situation $(0.77<1.54)$. Therefore, it is right to claim that in Persian direct advice giving mostly came from elder to younger. This result is companionable with the findings of other researchers (e. g., Sarfo, 2011) who investigated the effect of interlocutors' age and believe that this factor positively correlates with the degree of indirectness. In addition, the results showed that when the interlocutors were close or intimate they were mostly direct in giving advice. This finding coincides with previous literature (e. g., FélixBrasdefer, 2005; Salmani-Nodoushan, 2008) in that the more distant the relationship between the interlocutors, the more likely it is for them to use indirect communication strategies. Furthermore, according to the result, gender is not a significant factor in relation to directness in giving advice in Persian excluding one case (giving advice to an intimate interlocutor) in which women are more direct than men. This result is incongruent with the claims of other researchers (e.g., Lakoff, 1975; Goodwin, 1980; Tannen, 1990, 1994; Holmes, 2001) who believe that feminine speaker style is more indirect than that of men.

We as a researcher had a discussion with focused groups that were among some female students in a dormitory to establish an analysis of real and natural situation in Iranian context. Interesting enough, all of them agreed to utilize indirect strategies for giving advice to everybody in every age and level; they would also accept advice directly if a person impressed on them like a friend. Accordingly, they stated that their parents' advice is direct so that they apparently express their initial acceptance but will not put it into action. Specifically, one of them preferred to be silent and even if the person had asked her to express her idea about something or somebody, she would have given a piece of advice if necessary.

\section{Conclusion and Suggestion for Future Research}

This study, drawing upon Tannen's (1984) conversational style theory, investigated one aspect of communication style, i.e. indirectness, in the speech act of giving advice in Persian. The situations developed for this study, examined the effects of gender, age, status, and social distance, and asked the selected respondents to select among the common linguistic choices in Persian while giving advice. According to the findings, age, social distance, and status of the interlocutors had a significant effect on the linguistic choices of the participants and accordingly on their directness score. However, the results showed that there is no significant difference between the performances of males and females excluding the case of intimate females. That is, intimate females were more direct than intimate males. According to Tannen, whether the function of indirectness is defensiveness or solidarity depends on some factors such as context, conversational style of participants and the interaction of participants' styles and strategies. As it was already mentioned, the lowest degree of directness occurred when one of the interlocutors places in a higher status position. Therefore, lack of directness in giving advice in the higher status interlocutor situation, which was reflected in linguistic strategies of silence and indirectness, seems to be a sign of powerlessness in Persian. Accordingly, it was concluded that the function of indirectness in this situation was defensiveness. In other words, exercising power by the higher status interlocutor in this situation justifies the indirect/silent style of respondents. Another situation, which was preferred by the respondents, was giving advice to an older interlocutor. Although Tannen (1986) asserts that "power can masquerade as solidarity" (p. 94), in this situation, power relation was not present as a guiding clue to an indirect behavior. Therefore, we can conclude that solidarity justifies the indirect style of respondents in the referred situation. This function of indirectness obviously accounts for the selection of indirectness although it was in minority. Generally, the results of the present study showed that the functions of indirectness can be clearly justified by indirectness functions of Tannen's (1984) conversational style theory. This claim is supported both by the respondents' linguistic strategies and degree of directness/indirectness across different situations. Therefore, at least in Iranian context, conversational style theory of Tannen is the most efficient model for interpretation of indirectness phenomenon.

Considering the limitations of this study, other studies can be recommended for confirming the results of the present study. The first limitation has to do with the extent to which the findings can be generalized beyond the speech actbased studies. Although the large number of participants participated in this study has made the generalizability of results possible, it should be kept in mind that advice giving is only a speech act not the whole language. It seems that focusing on other speech acts such as apology, refusal, request, etc. is necessary to be sure about the linguistic choices and forms of indirectness in Persian. In addition, there is at least one caution that needs to be addressed concerning the methodology used with regard to this study. Further, other methods for examining indirectness such as self-perception questionnaires and interviews as well as other linguistic strategies such as silence vs. volubility, 
topic raising, interruption, and adversativeness or verbal conflict can be the subject of many comparative or interlanguage studies.

\section{References}

Afghari, A. (2007). A sociopragmatic study of apology speech act realization patterns in Persian. Speech Communication, 49, 177-185. http://dx.doi.org/10.1016/j.specom.2007.01.003

Aliakbari, M., Changizi, M. (2012). On the Realization of Refusal Strategies by Persian and Kurdish Speakers . International Journal of Intercultural Relations. $\quad 36(5) \quad 659-668$. http://dx.doi.org/10.1016/j.ijintrel.2012.04.009

Aliakbari, M., Heidarizadi, Z., and Mahjub, E. (2013). A Sociolinguistics Study of Conversational Swearing in Iran. International journal of linguistics. 5(3). 43-59. doi:10.5296/ijl.v5i3.3899 URL: http://dx.doi.org/10.5296/ijl.v5i3.3899

Allami, H. (2006). A sociopragmatic analysis of griping: The case of Iranian students. The Linguistics Journal, 1, 59-76.

Allami, H. (2010). A cross-linguistic study of refusals: An analysis of pragmatic competence development in Iranian EFL learners. Journal of Pragmatics, 43(1), 385-406. http://dx.doi.org/10.1016/j.pragma.2010.07.010

Al-Shboul, Y., \& Zarei, N. (2013). Gender differences in the appropriateness of advice-giving among Iranian EFL learners. International Journal of Language Learning and Applied Linguistics World (IJLLALW), 3(4), 88-98.

Arcidiacono, F., \& Pontecorvo, C. (2009). Cultural practices in Italian family conversations: Verbal conflict between parents and preadolescents. European Journal of Psychology of Education, 24(1), 97- 117. http://dx.doi.org/10.1007/BF03173477

Aufa, F. (2013). The Assessment Tool of L2 Learners' Pragmatic Competence: Written Discourse Completion Test (WDCT). International Proceedings of Economics Development \& Research, 68.

Borderia- Garcia, Ana. M. (2006). The acquisition of pragmatics in Spanish as a foreign language: Interpreting and giving advice. Unpublished Doctoral Dissertation. University of Iowa, Iowa, US.

Borger, R., Seaborne. A. E. M. (1967). The Psychology of Learning. Penguin.

Brown, P., Levinson, S. C. (1987). Politeness: Some universals of language use. Cambridge: Cambridge University Press.

Cardon, P. W. (2008). A critique of Hall's contexting model: A meta-analysis of literature on intercultural business and technical communication. Journal of Business and Technical Communication, 22 (4), 399. http://dx.doi.org/10.1177/1050651908320361

Charlebois, J. (2004). Pragmatics: The heart and soul of linguistic proficiency. The Language Teacher, 28(4), 3-8.

Cheng, L. (2009). Indirectness scale in Chinese request speech act. US-China Foreign Language, 7 (10), $51-60$.

Chun, M. Y. (2009). Cultural Relativity and Universality of Linguistic Politeness: The Speech Act of Advice. Unpublished doctoral dissertation. Korea University, Korea.

Culpeper, J. (2011). Impoliteness - Using Language to Cause Offence. Cambridge: University Press. http://dx.doi.org/10.1017/CBO9780511975752

Culpeper, J. (2008). Reflections on impoliteness, relational work and power in Bousfield, D \& Locher (eds.), M. Impoliteness in Language - Studies on its Interplay with Power and Practice. Berlin: Mouton de Gruyter.

DeCapua, A., \& Dunham, J. F. (2007). The pragmatics of advice giving: Cross-cultural perspectives. Intercultural Pragmatics, 4(3), 319-342. http://dx.doi.org/10.1515/IP.2007.016

De Francisco, V. P., \& Palczewski, C. H. (2007). Communicating gender diversity: A critical approach. Los Angeles: Sage Publications. http://dx.doi.org/10.4135/9781483329284

Ding, D. (2006). An indirect style in business communication. Journal of Business and Technical Communication, 20, 87-100. http://dx.doi.org/10.1177/1050651905281051

Eslami-rasekh, Z. (1993). A cross- cultural comparison of the requestive speech act realization patterns in Persian and American English. Pragmatics and Language Learning, 4, 85- 103.

Eslami-Rasekh, Zohreh. (2004). Face-keeping strategies in reaction to complaints: English and Persian. Journal of Asian Pacific Communication, 14(1), 179-195. http://dx.doi.org/10.1075/japc.14.1.11esl 
Eslami-Rasekh, A., Tavakoli, M, \& Abdolrezapur, P. (2010). Certainty and conventional indirectness in Persian and American request forms. The Social Sciences, 5(4), 332-339. http://dx.doi.org/10.3923/sscience.2010.332.339

Eslami-Rasekh, A., \& Ahmadian, M. J. (2011). A comparative study of reprimand strategies: Evidence from Iranian and American speech communities. The social Sciences, 6(1), 1-7. http://dx.doi.org/10.3923/sscience.2011.1.7

Esposito, A. (1979). Sex differences in children's conversation. Language and Speech, 22, 213 -220.

Farashiyan, A., \& Amirkhiz, S. Y. (2011). A descriptive-comparative analysis of apology strategies: The case of Iranian EFL and Malaysian ESL university students. English Language Teaching, 4(1), 224- 229. http://dx.doi.org/10.5539/elt.v4n1p224

Félix-Brasdefer, J. C. (20050. Indirectness and politeness in Mexican requests. In D. Eddington (Ed.), Selected Proceedings of the 7th Hispanic Linguistics Symposium (pp. 66-78). Somerville, MA: Cascadilla Proceedings Project.

Fung, L. (1975). A Study of indirectness in business meetings. The Southeast Asian Journal of English Language Studies, 15, 23- 39.

Garcia, C. (1993). Response to a request by native and non-native English speakers: Deference vs. camaraderie. Multilingua, 11(4). 387-406. http://dx.doi.org/10.1515/mult.1992.11.4.387

Goodwin, M. H. (1980). Directive- response speech sequences in girls' and boy's task activities. In S. McConnell-Ginet, R. Borker, \& N. Furman (Eds.), Women and Language in Literature and Society, (pp.157-73). New York: Praeger.

Gudykunst, W. B. (1983). Uncertainty reduction and predictability of behavior in low and high context cultures. Communication Quarterly, 31, 49-55. http://dx.doi.org/10.1080/01463378309369485

Gudykunst, W. B., Nishida, T. (1986). Attitudinal confidence in high and low-context cultures. Human Communication research, 12, 525-549. http://dx.doi.org/10.1111/j.1468-2958.1986.tb00090.x

Gudykunst, W. B., Yoon, Y.C. \& Nishida, T. (1987). The influence of individualism-collectivism on perceptions of in-group and out-group relationships. Communication Monographs, 54, 295-306. http://dx.doi.org/10.1080/03637758709390234

Hall, E. T. (1976). Beyond culture. New York: Doubleday

Hara, K., \& Kim, M. (2004). The effect of self-construals on conversational indirectness. International Journal of Intercultural Relations, 28(1), 1-18. http://dx.doi.org/10.1016/j.ijintrel.2003.12.005

Hassani, R., Mardani, M., \& Vahid D. H. (2011). A Comparative study of refusals: Gender distinction and social status in focus. Language Society and Culture, 32, 37-46.

Haugh, M. (2004). 'Revisiting the conceptualization of politeness in English and Japanese'. Multilingua, 23, 85-109. http://dx.doi.org/10.1515/mult.2004.009

Haugh, M. (2006a). 'Emic perspectives on the positive-negative politeness distinction'. Culture, Language and Representation, 3, 17-26.

Haugh, M. (2006b). 'Review of “Discourse politeness in Japanese conversation”'. Journal of Politeness Research, 2 , 313-317.

Haugh, M. (2007a). 'The discursive challenge to politeness theory: an interactional alternative'. Journal of Politeness Research, 3, 295-317. http://dx.doi.org/10.1515/PR.2007.013

Haugh, M. (2007b). 'Emic conceptualizations of (im)politeness and face in Japanese: implications for the discursive negotiation of second language learner identities'. Journal of Pragmatics, 39, 657-680. http://dx.doi.org/10.1016/j.pragma.2006.12.005

Hinkel, E. (1997). Appropriateness of advice: DCT and multiple choice data. Applied linguistics, 18 (1), 1-25. http://dx.doi.org/10.1093/applin/18.1.1

Holmes, J. (2001). An introduction to sociolinguistics (2nd Ed.). Harlow, England: Pearson Education.

Holtgraves, T. (1997). "Style of language use: Individual and cultural variability in Conversational indirectness. "Journal of Personality and Social Psychology, 73(3), 624-637. http://dx.doi.org/10.1037/0022-3514.73.3.624

James, D., Clarke, S. (1993). Women, men and interruptions: A critical review. In D. Tannen (Ed.), Gender and Conversational Interaction (pp. 231-280). New York: Oxford University Press. 
Jaworski, A. (1998). The silence of power and solidarity in Fallen Sons. Studia Anglica Posnaniensia: International Review of English Studies, 141(12), 143-151.

Kang, S.P. (1988). Korean culture, the Seoul Olympics, and world order. Korea and World Affairs, 12, 347-362.

Kasper, G. (1996). Developmental issues in ILP, Interlanguage pragmatics in SLA. Cambridge University Press, 272 , 2631-96.

Katriel, T. (1986). Talking Straight: Dugri Speech in Israel Sabra Culture. Cambridge: Cambridge University Press.

Lakoff, R. (1975). Language and Woman's Place. New York: Harper \& Row.

Lakoff, R. (1977). What you can do with words: politeness, pragmatics and performatives. In A. Rogers, B. Wall, \& J. Murphy (Eds.), Proceedings of the Texas conference on performatives, presuppositions, and implicatures (pp.79- 105). Arlington, VA: Center for Applied linguistics.

Leech, G. (1983). Principles of Pragmatics, London: Longman.

Li, H. Z. (2001). Cooperative and intrusive interruptions in inter- and interacultural dyadic discourse. Journal of Language and Social Psychology, 20(3), 259-284. http://dx.doi.org/10.1177/0261927X01020003001

Li, H. Z., Yum, Y., Yates, R., Aguilera, L., Mao, Y., \& Zheng, Y. (2005). Interruption and involvement in discourse: Can intercultural interlocutors be trained? Journal of Intercultural Communication Research, 34(4), 233-254.

Lim, T., Choi, S. (1996). Interpersonal relationships in Korea. In W. B. Gudykunst, S. Ting-Toomey, \& T. Nishida (Eds.), Communication in personal relationships across cultures (pp. 122-136). Thousand Oaks, CA: Sage.

Linnell, J., Porter, F. L., Stone, H., Chen, W. (1992). Can you apologize me? An investigation of speech act performance among non- native speakers of English. WPEL, 8(2), 33-53.

Littlewood, W. (1983). Communicative language teaching: An introduction. Cambridge: Cambridge University Press.

Locher, Miriam. (2006). Polite Behavior within Relational Work: The Discursive Approach to Politeness. In: Multilingua, 25 (3), 249-267. http://dx.doi.org/10.1515/multi.2006.015

Long, M. H. (1983a). Linguistic and conversational adjustments to nonnative speakers. Studies in Second Language Acquisition, 5, 177-194. http://dx.doi.org/10.1017/S0272263100004848

Márquez-Reiter, R. (2000). Linguistic politeness in Britain and Uruguay: A contrastive study of requests and apologies. Philadelphia, PA: John Benjamins. http://dx.doi.org/10.1075/pbns.83

Martínez-Flor, A., \& Fukuya, Y. J. (2005). The effects of instruction on learners' production of appropriate and accurate suggestions. System, 33(3), 463-480. http://dx.doi.org/10.1016/j.system.2005.06.007

Merkin, R. S. (2009). Cross-cultural communication pattern: Korean and American communication. Journal of intercultural communication, 20. Retrieved July 20, 2010 from www.immi.se/intercultural/nr20/merkin.html

Miller, G. A. (1974). Psychology, language and levels of communication. Human Communication: theoretical explorations. By A. Silverstein, 1-17. New York: J.Wiley.

Mwinyelle, J. B. (2005). The acquisition of pragmatic competence in an L2 classroom: Giving advice in Spanish. Unpublished Doctoral Dissertation. University of Texas, Austin, US.

Nelson, G. L., Al Batal, M., El Bakery, W. (2002). Directness vs. indirectness: Egyptian Arabic and US English communication style. International Journal of Intercultural Relations, 26, 39-57. http://dx.doi.org/10.1016/S0147-1767(01)00037-2

Nurani, L. M. (2009). Methodological issue in pragmatic research: Is discourse completion test a reliable data collection instrument? Jurnal Sosioteknologi Edisi, 17(8), 667- 678.

Pishghadam, R., \& Sharafadini, M. (2011). A Contrastive Study into the Realization of Suggestion Speech Act: Persain vs English. Canadian Social Science, 7(4), P230-239.

Renkema, J. (2004). Introduction to discourse studies. Amesterdam: John Benjamins Publishing. http://dx.doi.org/10.1075/z.124

Ružicková, E. (1998). Face, face-threatening acts and politeness in Cuban Spanish. Unpublished Doctoral Dissertation. University of Pittsburgh, Pittsburgh, PA.

Salmani-Nodoushan, M. A (2006). A comparative sociopragmatic study of ostensible invitations in English and Farsi. Speech Communication, 48(8), 903- 912. http://dx.doi.org/10.1016/j.specom.2005.12.001

Salmani- Nodushan, M. A (2008). Persian requests: Redress of face through indirectness. Iranian Journal of Language Studies (IJLS), 2(3), 257-280. 
Salmani-Nodoushan, M. A., Allami, H. (2011). Supportive discourse moves in Persian requests. International Journal of Language Studies (IJLS), 5(2), 65-94.

Sanchez- Burcks, J., Choi, I., Zhao, Sh., \& Nisbett, R. (2003). Conversing across cultures: East- West communication styles in work and nonwork contexts. Journal of Personality and Social Psychology, 85(2), 363372. http://dx.doi.org/10.1037/0022-3514.85.2.363

Sarfo, E. (2011). Variations in ways of refusing requests in English among members of a college community in Ghana. African Nebula, 3, 1-15.

Sattel, J. W. (1983). Men, inexpressiveness and power. In B. Thorne, C. Kramarae, \& N. Henley (Eds.), Language, Gender and Society (pp. 118-124). Rowley, MA: Newbury House

Searle, J. R (1975). Indirect speech acts. In P. Cole, \& J. Morgan (Eds.), Syntax and semantics (pp. 59-82). New York: Academic Press.

Shariati, M., Chamani, F. (2009). Apology strategies in Persian. Journal of Pragmatics, 42(6), 1689-1699. http://dx.doi.org/10.1016/j.pragma.2009.10.007

Shuy, R. W. (1982). Topic as the unit of analysis in a criminal law case. In: D. Tannen (Ed.), Analyzing Discourse: Text and talk (pp. 113-126). Washington, DC: Georgetown University Press.

Sifianou, M. (1992). Politeness phenomena in England and Greece: A cross-cultural perspective. Oxford, UK: Clarendon Press.

Spencer-Oatey, H. (2005). (Im)politeness, face and perceptions of rapport: unpackaging their bases and interrelationships. Journal of Politeness Research .1, 95-120. http://dx.doi.org/10.1515/jplr.2005.1.1.95

Spender, D. (1980). Talking Power and Equality. Retrieved July 16, 2010, from http://www.comm-dev/conf96/spender.htm

Takai, J., \& Lee, P. S. (2003). Japanese directness and indirectness across situations: Focusing on refining the in-group - out group distinction. Paper presented at the annual meeting of the International Communication Association. Retrieved 19 September, 2010, from http: www. Allacademic.com

Tannen, D. (1984). The pragmatics of the cross-cultural communication. Applied linguistic, 5(3), 189-195. http://dx.doi.org/10.1093/applin/5.3.189

Tannen, D. (1986). That's not what I meant! How conversational style makes or breaks relationships. New York: Ballantine Books.

Tannen, D. (1990). You just don't understand: Women and men in conversation. New York, NY: William Morrow.

Tannen, D. (1994). The relativity of linguistic strategies: rethinking power and solidarity in gender and dominance. In D. Tannen (Ed.), Gender and Discourse (pp. 19-52). New

York: Oxford University Press.

Thomas, J. (1983). Cross-cultural pragmatic failure. Applied Linguistics, 4(2), 91-112. http://dx.doi.org/10.1093/applin/4.2.91

Watts, R. (2003). Politeness. Cambridge: University Press. http://dx.doi.org/10.1017/CBO9780511615184

Wierzbicka, A. (2003). Cross-cultural pragmatics: The semantics of human interaction (2 ${ }^{\text {nd }}$ Ed.). Berlin: Mouton de Gruyter. http://dx.doi.org/10.1515/9783110220964

Wilson, D. (1987). 'Relevance and Understanding' in G Brown, K Malkmjaer, A Polbtt, and J Williams (eds) 1994 Language and Understanding. Oxford Oxford University Press

Xiao, X., Zhao, Ch., \& Zhang, Sh. (2007). Do we talk differently? Cross culture study on conference call. In N. Aykin (Ed.), Proceedings of Usability and Internationalization: Vol. 38. HCI and Culture (637- 645). Springer-Verlag Berlin, Heidelberg. http://dx.doi.org/10.1007/978-3-540-73287-7_74

Zaharna, R. S. (1995). Understanding cultural preferences of Arab communication patterns. Public Relations Review, 21, 241-255. http://dx.doi.org/10.1016/0363-8111(95)90024-1

Zhang, F., You, H. (2009). Motives of indirectness in daily communication: An Asian perspective. Asian Culture and History, 1(2), 99-102. http://dx.doi.org/10.5539/ach.v1n2p99

Zimmerman, D., Candace. W. (1975). Sex roles, interruptions and silences in conversation. In B. Thorne, \& N. Henley (Eds.), Language and sex: difference and dominance (pp. 105-129). Rowley, Mass: Newbury House. 